JOURNAL OF

SYNCHROTRON

RADIATION

ISSN 1600-5775

Received 15 July 2021

Accepted 22 October 2021

Edited by W. Shi, Institute of High Energy Physics, People's Republic of China

Keywords: X-ray absorption spectroscopy; XAS; actinide; electrochemistry; radioactive sample; neptunium chemistry.

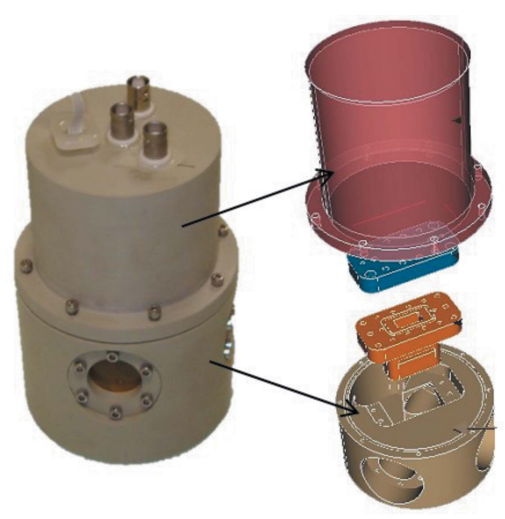

OPEN $\odot$ ACCESS

\section{X-ray absorption spectroscopy and actinide electrochemistry: a setup dedicated to radioactive samples applied to neptunium chemistry}

\author{
Richard Husar, ${ }^{a}$ Thomas Dumas, ${ }^{a} *$ Michel L. Schlegel, ${ }^{\mathrm{b} *}$ Daniel Schlegel, ${ }^{\mathrm{c}}$ \\ Dominique Guillaumont, ${ }^{\text {a }}$ Pier-Lorenzo Solari ${ }^{d}$ and Philippe Moisy ${ }^{\mathrm{a}}$
}

${ }^{a}$ CEA, DES, ISEC, DMRC, Université de Montpellier, Marcoule, France, ${ }^{\mathbf{b}}$ CEA, DES-Service d'Etudes Analytiques et de Réactivité des Surfaces (SEARS), CEA, Université Paris-Sacly, 911191 Gif-sur-Yvette, France, 'ESTA-École Supérieure des Technologies et des Affaires, 90004 Belfort Cedex, France, and ${ }^{\mathbf{d}}$ Synchrotron SOLEIL, L'Orme des Merisiers Saint-Aubin, BP 48, 91192 Gif-sur-Yvette Cedex, France. *Correspondence e-mail: thomas.dumas@cea.fr, michel.schlegel@cea.fr

A spectroelectrochemical setup has been developed to investigate radioactive elements in small volumes $(0.7$ to $2 \mathrm{ml})$ under oxidation-reduction (redox) controlled conditions by X-ray absorption spectroscopy (XAS). The cell design is presented together with in situ XAS measurements performed during neptunium redox reactions. Cycling experiments on the $\mathrm{NpO}_{2}{ }^{2+} / \mathrm{NpO}_{2}{ }^{+}$redox couple were applied to qualify the cell electrodynamics using XANES measurements and its ability to probe modifications in the neptunyl hydration shell in a $1 \mathrm{~mol} \mathrm{l}^{-1} \mathrm{HNO}_{3}$ solution. The XAS results are in agreement with previous structural studies and the $\mathrm{NpO}_{2}{ }^{2+} / \mathrm{NpO}_{2}{ }^{+}$standard potential, determined using Nernst methods, is consistent with measurements based on other techniques. Subsequently, the $\mathrm{NpO}_{2}{ }^{+}, \mathrm{NpO}_{2}{ }^{2+}$ and $\mathrm{Np}^{4+}$ ion structures in solution were stabilized and measured using EXAFS. The resulting fit parameters are again compared with other results from the literature and with theoretical models in order to evaluate how this spectroelectrochemistry experiment succeeds or fails to stabilize the oxidation states of actinides. The experiment succeeded in: (i) implementing a robust and safe XAS device to investigate unstable radioactive species, (ii) evaluate in a reproducible manner the $\mathrm{NpO}_{2}{ }^{2+} / \mathrm{NpO}_{2}{ }^{+}$standard potential under dilute conditions and (iii) clarify mechanistic aspects of the actinyl hydration sphere in solution. In contrast, a detailed comparison of EXAFS fit parameters shows that this method is less appropriate than the majority of the previously reported chemical methods for the stabilization of the $\mathrm{Np}^{4+}$ ion.

\section{Introduction}

In situ X-ray absorption spectroscopy (XAS) in combination with electrochemical techniques is a powerful combination for determining the coordination of metal ions at a controlled oxidation state in various electrolytes (Nockemann et al., 2009; Achilli et al., 2016). Such an in situ approach is nowadays commonly applied for $d$-block elements and rare earth compounds, but is still very limited for actinide elements (An). These elements display unusual redox properties and complexation behaviour (Brown, 1978). Understanding the equilibria between oxidized and reduced species, the formation of intermediate unstable species and the magnitude of relevant redox couples under the conditions of interest is essential for predicting An chemistry in industrial and natural environments. Specifically, the characterization of intermediate species or unstable oxidation states is of fundamental interest in understanding how the internal structures of An molecular complexes affect their reactivity and the exchange between oxidation states. 
To investigate these reactions at the molecular scale using XAS, a spectroelectrochemical cell was designed at Argonne National Laboratory (USA) (Antonio et al., 1997). The limited volume of this cell $(5 \mathrm{ml})$ allowed for the characterization of radioactive samples using a limited amount of hazardous radionuclide with a concentration range $\left(10^{-2}\right.$ to $\left.10^{-4} \mathrm{~mol}^{-1}\right)$ that corresponds to XAS measurements. Thus, this cell has been used to investigate An redox chemistry under acidic conditions (Soderholm et al., 1999), alkaline conditions (Williams et al., 2001) and on frontier elements such as berkelium (Antonio et al., 2002). Subsequent XAS research monitoring actinide and radioactive elements coordination during in situ electroactive processes was performed with less active nucleides, such as U (Hennig et al., 2005) or Tc (Antonio et al., 2002; Poineau et al., 2006). Although highactivity samples $(\mathrm{Np}$ and $\mathrm{Pu}$ ) were used in several experiments in recent years, their combination with an electrochemical setup was hampered for various safety reasons. To contribute to this effort and to overcome these limitations, we have developed an electrochemical-XAS setup available for highactivity samples. The setup was designed taking into account specific requirements: (i) a small sample volume to limit radioactivity and permit the study of highly radioactive materials; (ii) the possibility to perform reproducible electrochemical reactions in situ (i.e. directly on the beamline) with highly radioactive material during an XAS experiment; (iii) (moderate) flexibility in the choice of working, reference and counter electrodes; (iv) easy access and handling to limit the risk of spillover during sample preparation; (v) tightness and number of barriers satisfying the synchrotron safety requirements for the handling of radioactive samples; and (vi) a small overall size to facilitate transport between the synchrotron facility and actinide laboratories. The cell has been successfully implemented on the MARS beamline at the

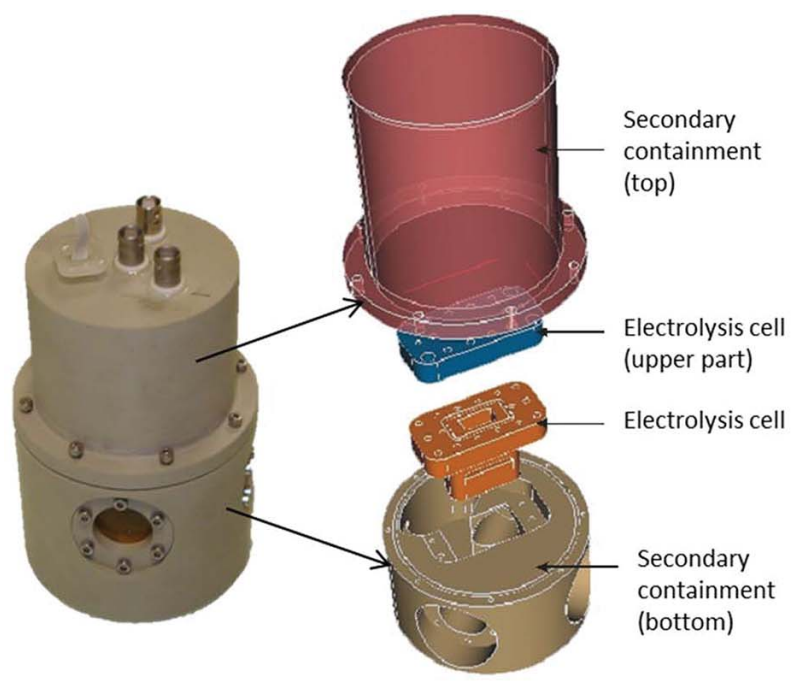

SOLEIL synchrotron (LLorens et al., 2014). The first set of experiments was performed in $1 \mathrm{MNHO}_{3}$ to follow in situ structural and electronic changes of the neptunium ions under potentiometric control. The results demonstrate the capacities and limits of such a microcell setup and are discussed in comparison with purely $\mathrm{Np}$ electrochemistry results (i.e. laboratory scale and no X-ray techniques) (Cohen \& Hindman, 1952; Cohen et al., 1954; Takao et al., 2009; Hindman et al., 1958; Sornein et al., 2009; Kihara et al., 1999; Kim et al., 2004, 2005; Cohen, 1961; Zielen et al., 1958) or previous structural XAS studies (Bonin et al., 2009; Allen et al., 1997; Di Giandomenico et al., 2009; Combes et al., 1992; Reich et al., 2000; Soderholm et al., 1999; Hennig et al., 2005; Williams et al., 2001; Den Auwer et al., 1999; Scheinost et al., 2016; Antonio et al., 1997, 2001, 2012; Ikeda-Ohno et al., 2008, 2009).

While the main aim was to check the ability of the setup to proceed safely with the combination of electrochemistry and XAS measurements under confined conditions, a more critical evaluation of the structural results is also proposed. The systematic comparison of the structural EXAFS parameters extracted from (i) this work, (ii) formal works and (iii) theoretical calculations is proposed. This allows for a better understanding of the main benefits of such an electrochemical cell concept, but also some limitations that should not be ignored.

\section{MARS electrochemical-XAS setup}

The setup was designed to facilitate electrochemical control of a limited volume $(700$ to $2000 \mu \mathrm{l})$ of radioactive solution or suspension while at the same time guaranteeing double confinement of these hazardous samples and allowing relatively easy handling in the laboratory and on the beamline. The setup was made of an inner cell and an outer envelope



Figure 1

(Left) Double confinement electrochemical-XAS setup, $0.7<V_{\text {sol }}<2 \mathrm{ml}$ (a magnetic stirrer is placed at the bottom of the setup). (Right) The electrolysis cell at the MARS beamline CX3 end-station. 
(Fig. 1). The inner cell is made of PEEK, a material that is relatively inert, and thus can be used for acidic, basic and even non-aqueous solutions compatible with this material (such as room-temperature ionic liquids and organic solutions like dodecane or heptane). Two X-ray windows are obtained by locally thinning the inner cell walls down to $200 \mu \mathrm{m}$. This design limits the risk of leaking at the X-ray windows, while providing a moderate $\mathrm{X}$-ray attenuation $(95 \%$ of the $\mathrm{X}$-ray flux transmitted at $17 \mathrm{keV}$ ). This cell is enclosed in a secondary containment, also made of PEEK, to prevent dispersion in case of inner cell failure. The inner cell is rotated at $45^{\circ}$ with respect to the incident beam, and three windows made of $90 \mu \mathrm{m}$ Kapton film sealed with three screwed clamping rings to the second envelope provide paths for the incident beam, the transmitted beam and the fluorescence signal. The path length of the transmitted X-ray beam in the inner cell is about $11 \mathrm{~mm}$.

The volumes of liquid that can be introduced in the inner cell vary between 750 (the minimum volume to soak up the windows) and $2000 \mu$ l. The bulk solution is steered (600 rpm) by a magnetic bar driven by a stirrer located outside the second envelope. Bulk electrolysis is then performed in the inner cell.

The electrodes are screwed and glued onto the lid of the inner cell to further limit possible leaking of fluids. The nature and distribution of electrodes can be tailored to meet the need of a specific experiment. For example, the working electrode can be made of platinum or any other metallic material, or even carbon. Our conventional reference electrode is an $\mathrm{Ag} /$ $\mathrm{AgCl}$ microelectrode (World Precision Instruments). However, any other microelectrode could in principle be used, provided it can fit through the inlet (4 $\mathrm{mm}$ in diameter) and be reasonably short (a few $\mathrm{cm}$ ) and sturdy. In a more recent experiment, a homemade reference electrode dedicated to room-temperature ionic liquids was also used in the same cell (Bengio et al., 2018, 2020). The counter-electrode can plunge directly into the solution or, alternatively, it can be isolated from the main solution by a tube closed by a porous frit acting as a salt bridge. This setup somewhat hinders parasitic reactions on the electrode surface which might disturb the desired reaction of actinide redox transformation.

The setup performance was assessed by experiments of $\mathrm{Np}$ redox in $1 \mathrm{M} \mathrm{HNO}_{3}$. The working electrode is a platinum coiled electrode and the auxiliary electrode is Pt wire separated from the buck by a tube closed by a porous frit. The reference electrode is a $2 \mathrm{~mm}$-diameter $\mathrm{Ag} / \mathrm{AgCl}$ microelectrode from World Precision Instrument. Preliminary tests with the counter-electrode bathed directly in the experimental solution failed to achieve quantitative oxidation (or reduction) up to the target oxidation state although the target potentials had been validated previously by spectroelectrochemical UVVis absorption spectroscopy. Instead of a progressive change in oxidation state under the applied conditions, competitive side reactions seems to occur and are manifested by important current flow but no significant changes in redox speciation. For the later experiments, the counter-electrode was placed in the frit-sealed tube, which resulted in a reproducible experiment that is presented in the following results.

\section{Experimental}

\subsection{Sample preparation}

The sample preparation was performed in a radiochemistry laboratory at the ATALANTE facility (CEA Marcoule, France) in a dedicated glove-box. The purity of the oxidation state of the $\mathrm{Np}^{\mathrm{V}}$ stock solution was checked with a UV-Vis spectrometer (Carry). A sample of $0.1 \mathrm{mM} \mathrm{Np} \mathrm{N}^{\mathrm{V}}$ was transferred to the inner cell via a dedicated holder. The filling hole was then closed with a screw and sealed with epoxy glue. Basic tests were performed in the laboratory to check for a correct electrochemical behaviour of the cell. The second envelope was then closed and the cell can be easily shipped due to its relatively small size.

\subsection{XAS experiment}

The electrochemical cell was installed on the CX3 station of the MARS beamline, which is dedicated to XAS (Jeanson et al., 2009; LLorens et al., 2014). A 13-element HPGe solid-state detector (ORTEC) was used to collect the $\mathrm{Np}$ signal in fluorescence mode. The energy calibration of the monochromator was performed at the yttrium $K$-edge. All measurements were performed at room temperature.

\subsection{Bulk electrolysis}

Bulk electrolysis was performed over a period of $30 \mathrm{~min}$ using a remote-controlled potentiostat ( $\mu$ Autolab, Metrohm) located in the experimental hutch. Chrono-amperometric sequences of $30 \mathrm{~min}$ were alternated with acquisition of XAS data. It is worth mentioning that shorter electrolysis times or simultaneous electrolysis-XAS acquisition may artificially suggest hysteresis on $\mathrm{Np}$ redox couples under the chosen conditions, a consequence of incomplete or ongoing electrolysis. Moreover, the recorded chronoamperogram, even indicating the exponential shape expected for dilute solution electrolysis, never reached a null current during the experiment, indicating parasitic reactions.

Data processing was carried out using the Athena code (Ravel \& Newville, 2005). The $E_{0}$ energy was set at the maximum of the absorption edge. The EXAFS signal was extracted by subtracting a linear pre-edge background and a combination of cubic spline functions for the atomic absorption background and for normalizing the signal by the Lengeler-Eisenberg procedure. Fourier transforms (FT) were obtained by Fourier transform in $k^{3} \chi(k)$ between 2.5 and $11 \AA^{-1}$. Selected FT contributions were fitted in $R$-space over individual radial distances and Debye-Waller factors $\left(\sigma^{2}\right)$ for every considered distance, using backscattering amplitude and phase shift functions obtained with FEFF8.2 (Rehr \& Albers, 2000) performed on structures optimized by density functional theory (DFT) calculations (see $\S 4, D F T$ calculations). The amplitude reduction factor $E_{0}{ }^{2}$ was set at 0.9. All fitting operations were performed. The $R$ factor (\%) and errors in distances were provided by ARTEMIS (Ravel \& Newville, 2005). 


\section{DFT calculations}

The geometry and frequency calculations were performed with GAUSSIAN16 (Frisch et al., 2016) at the DFT level of theory. A small core quasi-relativistic effective core potential (RECP-60 electrons) (Cao \& Dolg, 2004; Küchle et al., 1994) by the Stuttgart-Cologne group and its corresponding TZvalence basis set were used for the neptunium ion. The PBE0 functional was used with the def-TZVP (Schäfer et al., 1994) basis sets for $\mathrm{O}$ and $\mathrm{H}$ atoms. Aqueous solvation effects were taken into account using two explicit hydration shells. Effects beyond the second hydration shell were described through an implicit solvation model. The Integral Equation Formalism Polarizable Continuum Model (IEFPCM) was used as implemented in GAUSSIAN16.

The $a b$ initio Debye-Waller factors $\left(\sigma^{2}\right)$ were calculated at $300 \mathrm{~K}$ for each scattering path from the dynamical matrix extracted from the DFT frequency calculations with the DMDW module of FEFF9 (Rehr et al., 2010; Rehr \& Albers, 2000).

\section{Results}

\section{1. $\mathrm{Np}^{\mathrm{VI} / \mathrm{Np}^{\mathrm{V}}}$}

The first electrolysis experiment was performed with an initial $\mathrm{Np}^{\mathrm{V}}$ solution. XANES and EXAFS spectra were recorded after $30 \mathrm{~min}$ of electrolysis for each potential step at $850,950,975,1000,1025$ and $1150 \mathrm{mV} /(\mathrm{Ag} / \mathrm{AgCl})$ in the oxidation (anodic) direction, and at 1150, 1050, 975, 950, $925,900,875,800$ and $750 \mathrm{mV} /(\mathrm{Ag} / \mathrm{AgCl})$ in the reduction (cathodic) direction (Fig. 2). All XANES spectra display a white line, which is shifted from 17616 to $17619.5 \mathrm{eV}$ as $\mathrm{Np}^{\mathrm{V}}$ is oxidized to $\mathrm{Np}^{\mathrm{VI}}$. The high-energy shoulder of the absorption edge, located near $17628 \mathrm{eV}$ and attributed to multiple scattering in the neptunyl moiety, is also shifted to higher energy, i.e. $17634 \mathrm{eV}$, consistent with a trans-dioxo structure for both $+\mathrm{V}$ and the $+\mathrm{VI}$ oxidation states. Conversely, a shift of the white line and of the shoulder back to their initial values is measured during the reduction steps of $\mathrm{Np}^{\mathrm{VI}}$ back to $\mathrm{Np}^{\mathrm{V}}$. From $\mathrm{Np}^{\mathrm{V}}$ to $\mathrm{Np}^{\mathrm{VI}}$, the white line increases in intensity. An isosbestic point at $17617.7 \mathrm{eV}$ repeats itself in both the oxidation and the reduction sequences, suggesting that only two components were simultaneously present in solution for each sequence. Transitional spectra were reproduced by linear combination fits using the two extrema spectra for $\mathrm{Np}^{\mathrm{v}}$ and $\mathrm{Np}^{\mathrm{VI}}$, resulting in $\mathrm{Np}^{\mathrm{IV}} / \mathrm{Np}^{\mathrm{V}}$ ratios for each potential. As pointed out by Soderholm et al. (1999), a direct estimation of the redox species is only possible if there is no change in the experimental setup during the data acquisition except for the imposed potential in the solution.

The relative $\mathrm{Np}^{\mathrm{VI}} / \mathrm{Np}^{\mathrm{V}}$ concentrations are determined with a linear combination fit from the two extrema spectra. This can be used in a Nernst plot as $\log \left(\left[\mathrm{Np}^{\mathrm{VI}} / \mathrm{Np}^{\mathrm{V}}\right]\right)$ plotted as a function of the applied potential (Fig. 3). Both data sets from the oxidation (red) and reduction (blue) experiments are well aligned within error bars. This evidences the reversibility of the $\mathrm{Np}^{\mathrm{VI}} / \mathrm{Np}^{\mathrm{V}}$ redox system, confirming that the electro-
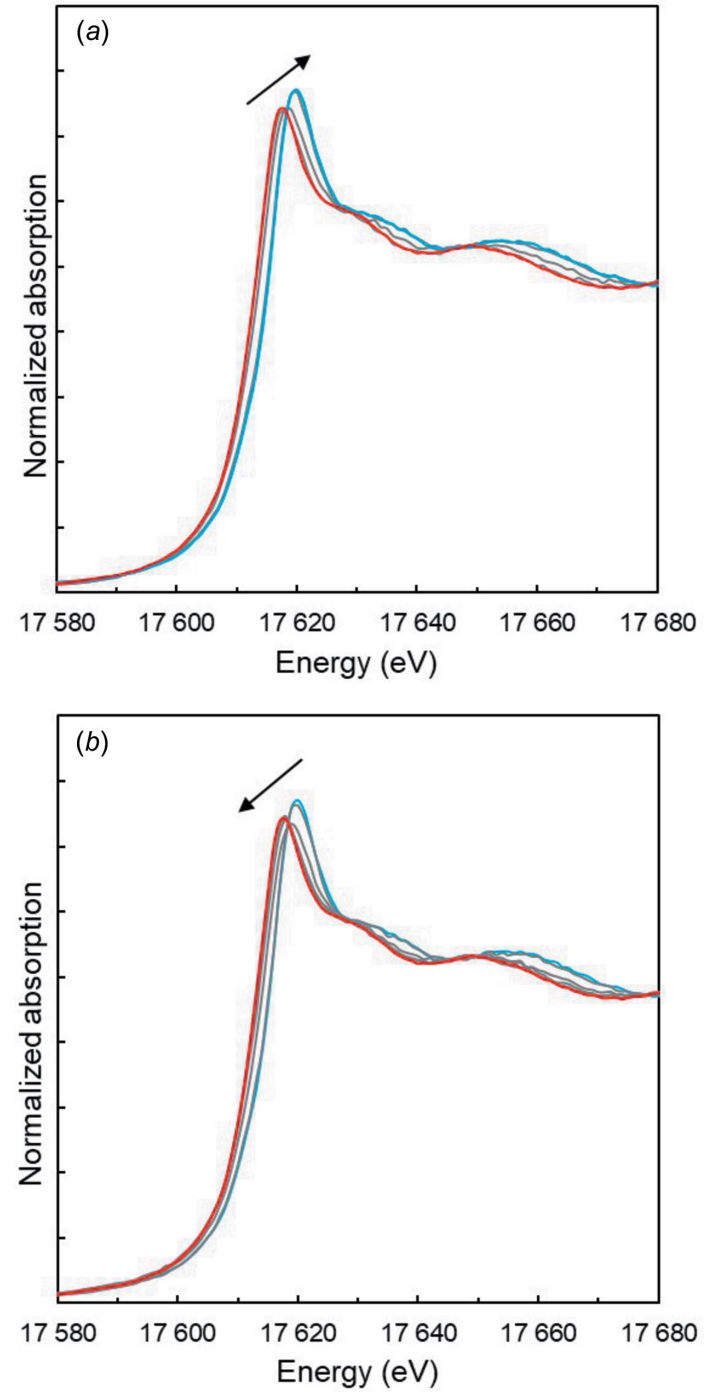

Figure 2

Normalized $\mathrm{Np} L_{3}$-edge XANES spectrum for $(a)$ oxidation and $(b)$ reduction experiments. The red spectrum is the pure $\mathrm{Np}^{\mathrm{V}}$ XANES spectrum and the blue spectrum is the pure $\mathrm{Np}^{\mathrm{VI}}$ XANES spectrum. The grey spectrum resamples intermediate states.

chemical setup operates as expected. From the Nernst plot, a formal potential of the $\mathrm{Np}^{\mathrm{VI}} / \mathrm{Np}^{\mathrm{V}}$ redox couple in $1 M \mathrm{NHO}_{3}$ is determined by linear regression (Fig. 3, red and blue dotted lines), according to

$$
E=E^{0 \prime}+(2.3 R T / n F) \log \left(\left[\mathrm{Np}^{\mathrm{VI}}\right] /\left[\mathrm{Np}^{\mathrm{V}}\right]\right)
$$

where $E$ is the potential, $E^{0 \prime}$ is the apparent standard potential, $R$ is the perfect gas constant $\left(\mathrm{J} \mathrm{mol}^{-1} \mathrm{~K}^{-1}\right), \quad T$ is temperature $(\mathrm{K}), n$ is the number of electrons in the reaction, $F$ is the Faraday constant and $\left[\mathrm{Np}^{\mathrm{VI}}\right]$ and $\left[\mathrm{Np}^{\mathrm{V}}\right]$ are the relative concentrations in $\mathrm{Np}^{\mathrm{VI}}$ and $\mathrm{Np}^{\mathrm{V}}$, respectively, as determined by the linear combination fit of the neptunium $L_{3}$-edge spectra.

The slopes, ranging between 55.5 and $58.2 \mathrm{mV}( \pm 8 \mathrm{mV})$, are in reasonable agreement with a single electron transfer (expected value of $59 \mathrm{mV}$ at $T=298 \mathrm{~K}$ ). The two formal potentials obtained from the oxidation and reduction experi- 


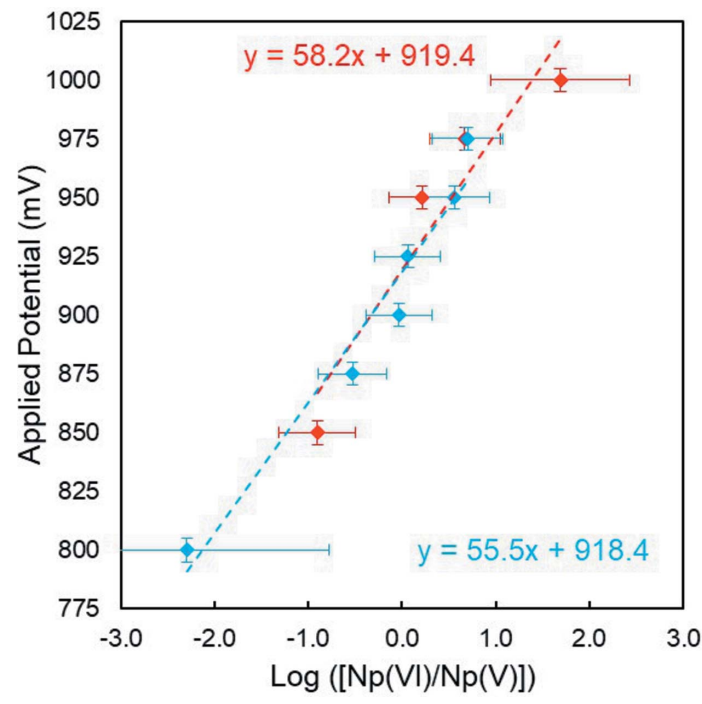

Figure 3

Nernst plots obtained from XANES measurements. Red diamonds correspond to the oxidizing experiment and blue diamonds to the reducing experiment. The dashed lines are the linear regression.

ments are 918.7 and $918.4 \mathrm{mV} /(\mathrm{Ag} / \mathrm{AgCl})$, respectively. Herein, the $\mathrm{Np}^{\mathrm{VI}} / \mathrm{Np}^{\mathrm{V}}$ formal potential given with a maximum uncertainty of $\pm 10 \mathrm{mV}$ is in good agreement with similar studies performed in perchloric acid (Soderholm et al., 1999; Antonio et al., 2001) or recent work from Chatterjee et al. (2017) in nitric acid using equivalent spectrophotometric methods.

5.1.1. EXAFS analysis. From electrolysis experiments and analysis of XANES spectra, we demonstrated that the setup provides a fairly robust and reliable method to isolate $\mathrm{Np}^{\mathrm{VI}}$ and $\mathrm{Np}^{\mathrm{V}}$ oxidation states by electrolysis. With the potentials set at 1150 and $750 \mathrm{mV} /(\mathrm{Ag} / \mathrm{AgCl})$, we expect to stabilize pure species for EXAFS analysis. This controlled potential may stabilize the Np oxidation state upon long EXAFS measurements, thereby balancing for the in situ photooxidation due to beam damage. The purpose of the following section is to evaluate whether the electrochemically purified solution results in a more reliable solution to isolate both neptunium oxidation-state ions in a simple solution. In order to compare the results with previous EXAFS measurements on similar systems, we propose to compare the significant fit parameters (CN and DWF) on a single plot. First, Fig. 4 shows the $k^{3}$ weighted EXAFS oscillations and Fourier transform (FT) for both $\mathrm{Np}^{\mathrm{V}}$ - and $\mathrm{Np}^{\mathrm{VI}}$-stabilized solutions. Neptunyl ion hydrates show two main oscillations corresponding to two FT peaks typical for hydrated actinyl oxocation (Allen et al., 1997; Bolvin et al., 2001; Di Giandomenico et al., 2009; Duvail et al., 2019). The structural parameters from simple two oxygen shell EXAFS fits are summarized in Table 1. The coordination spheres of $\mathrm{Np}^{\mathrm{VI}}$ and $\mathrm{Np}^{\mathrm{V}}$ are formed by two $\mathrm{O}$ atoms from the neptunyl moiety $\left(\mathrm{O}_{\mathrm{yl}}\right)$ at short $R_{(\mathrm{Np}-\mathrm{Oyl})}$ distances of 1.75 and $1.82 \AA$, respectively, and by about 4.4 and 4.9 equatorial $\mathrm{O}$ atoms $\left(\mathrm{O}_{\mathrm{eq}}\right)$ from water molecules at longer $R_{(\mathrm{Np}-\mathrm{Oeq})}$ distances of 2.41 and $2.51 \AA$, respectively. Overall, these results are in line with published values and confirm that a
Table 1

Metrical parameters from EXAFS fits.

Asterisks (*) indicate fixed parameters.

\begin{tabular}{lllll}
\hline & Path & $N$ & $R$ & $\sigma^{2}$ \\
\hline $\mathrm{Np}^{\mathrm{vI}}$ & $\mathrm{O}_{\mathrm{yl}}$ & $2^{*}$ & $1.75(1)$ & $0.0022(10)$ \\
$\Delta E_{0} 5 \mathrm{eV}$ & $\mathrm{O}_{\mathrm{H} 2 \mathrm{O}}$ & $4.6(7)$ & $2.41(2)$ & $0.0035(15)$ \\
$R$ factor $2.1 \%$ & & & & \\
& & & & \\
$\mathrm{~Np}^{\mathrm{V}}$ & $\mathrm{O}_{\mathrm{yl}}$ & $2^{*}$ & $1.82(1)$ & $0.0019(10)$ \\
$\Delta E_{0}-1 \mathrm{eV}$ & $\mathrm{O}_{\mathrm{H} 2 \mathrm{O}}$ & $4.9(6)$ & $2.51(2)$ & $0.0060(15)$ \\
$R$ factor $1.8 \%$ & & & & \\
\hline
\end{tabular}

single oxidation state predominates in solution. Distances correspond to the values reported in the literature within a maximum deviation of $0.02 \AA$ (Combes et al., 1992; Allen et al., 1997; Antonio et al., 1997, 2001; Den Auwer et al., 1999; Reich et al., 2000; Bolvin et al., 2001; Williams et al., 2001; Kim et al., 2004; Denecke et al., 2005; Kim et al., 2005; Ikeda-Ohno et al., 2008; Di Giandomenico et al., 2009; Hennig et al., 2009; Takao et al., 2009). However, the hydration numbers $\left(N_{\text {Oeq }}\right)$ are known to be much less accurately determined from the EXAFS fits and are still actively discussed. For $\mathrm{Np}^{\mathrm{VI}}$, the $N_{\text {Oeq }}$ values from previous EXAFS measurements range between 4.6 and 5.3. For $\mathrm{Np}^{\mathrm{v}}$, the $N_{\text {Oeq }}$ values are between 3.6 and 5.2.

The large dispersions reported in the literature are likely due to the mathematical correlation observed in a fitting procedure between the number of scattering atoms in a given shell $(N)$, the Debye-Waller factor $\left(\sigma^{2}\right)$ and the value of the total amplitude reduction factor $\left(S_{0}^{2}\right)$. Although there is no physical meaning between these physical parameters, upon an EXAFS fit the three parameters $N, S_{0}^{2}$ and $\sigma^{2}$ result in similar effects on the oscilation amplitudes. It is therefore difficult to



Figure 4

Experimental FT EXAFS signal (line) and best fits (open circles) obtained after $30 \mathrm{~min}$ electrolysis at $1150 \mathrm{mV} /(\mathrm{Ag} / \mathrm{AgCl})$ (blue) and at $750 \mathrm{mV} /(\mathrm{Ag} / \mathrm{AgCl})$ (red). The inset is the corresponding $k^{3}$-weighted EXAFS oscillations. 
address coordination numbers from a single EXAFS signal with perfect accuracy, especially if the $k$ range is short.

In order to estimate the magnitude of these correlations and allow a good comparison between previous EXAFS fits performed under different conditions (i.e. fixed or floating $\mathrm{CN}$ values and $\sigma^{2}$ ), a more complete EXAFS data analysis is proposed hereafter. This analysis follows a method proposed by Ikeda-Ohno et al. (2008). $N_{\text {Oeq }}$ is successively fixed from 3 to 6 and, for each coordination number step, a best fit is performed. This results in the determination of a conditional $\sigma^{2}$ variation as a function of $N$. The results can be displayed on a $\sigma^{2} N$ plot, as proposed by Ikeda-Ohno et al. (2008) (Fig. 5). The best $N_{\text {Oeq }}$ and $\sigma^{2}$ combinations (corresponding to Table 1; values for $\mathrm{Np}^{\mathrm{V}}$ and $\mathrm{Np}^{\mathrm{VI}}$ ) are plotted as triangles in Fig. 5 .



(a)

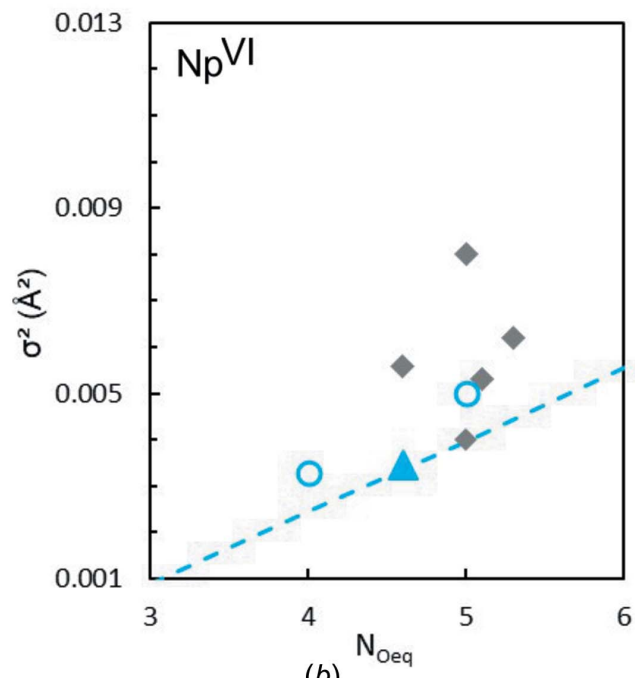

Figure 5

$\sigma^{2} N$ plots from the $\mathrm{Np}^{\mathrm{VI}}$ and $\mathrm{Np}^{\mathrm{V}}$ fits. Blue and red dashed lines are the $\sigma^{2}$ variation as a function of $N_{\text {Oeq }}$ for $\mathrm{Np}^{\mathrm{VI}}$ and $\mathrm{Np}^{\mathrm{V}}$, respectively. Previous reported single-point fit values are given as grey diamonds (Antonio et al., 2001; Ikeda-Ohno et al., 2008, 2009; Hennig et al., 2009; Di Giandomenico et al., 2009; Combes et al., 1992; Allen et al., 1997; Reich et al., 2000; Scheinost et al., 2016; Denecke et al., 2005). The open circles are DFTcalculated parameters.
For $\mathrm{Np}^{\mathrm{V}}$ (Fig. 5, red dashed line) and $\mathrm{Np}^{\mathrm{VI}}$ (Fig. 5, blue dashed line) the $\sigma^{2}$ values were found to vary approximately linearly with $N_{\text {Oeq }}$. The $\mathrm{Np}^{\mathrm{V}}$ trend is similar to that reported by Ikeda-Ohno et al. (2008) for $\mathrm{Np}^{\mathrm{V}}$. The corresponding $R$ factors follow a parabolic variation (not shown) with a minimum at $N_{\text {Oeq }}=4.9$ for $\mathrm{Np}^{\mathrm{V}}$ and a minimum at $N_{\text {Oeq }}=4.6$ for $\mathrm{Np}^{\mathrm{VI}}$. However, for both $\mathrm{Np}^{\mathrm{VI}}$ and $\mathrm{Np}^{\mathrm{V}}$, reasonable fit parameters were obtained for all tested $N_{\text {Oeq }}$ values (i.e. $R_{\mathrm{F}}<$ $5 \%$ and $\sigma^{2}<0.015 \AA^{2}$ ). This is the reason why this semiempirical methodology was applied to compare the data with previous results whatever the method used to fit the data. Since the fit can be performed assuming multiple $N_{\text {Oeq }}$ values, a relevant comparison with any single data point from previous reports needs to be achieved toward the full $N_{\text {Oeq }}$ range.

On Fig. 5, the grey diamonds are previous fit parameters determined under similar chemical conditions (i.e. noncomplexing and acidic solution). Both ex situ measurements (i.e. chemical preparation) (Hennig et al., 2009; Ikeda-Ohno et al., 2008; Di Giandomenico et al., 2009; Allen et al., 1997; Reich et al., 2000; Combes et al., 1992) and in situ measurements by spectroelectrochemistry (Antonio et al., 2001) are compared with $\mathrm{Np}^{\mathrm{V}}$ and $\mathrm{Np}^{\mathrm{VI}}$ fit parameters from this work. For a given $N_{\text {Oeq }}$ value, the $\sigma^{2}$ values (dashed blue and red lines) determined in this work are comparable with or lower than previously published $\sigma^{2}$ parameters. This is a good indication for a lower disorder/higher purity in this work where $\mathrm{Np}^{\mathrm{V}}$ and $\mathrm{Np}^{\mathrm{VI}}$ were purified electrochemically.

Concomitantly, a comparison of the $\mathrm{Np}^{\mathrm{V}}$ and $\mathrm{Np}^{\mathrm{VI}}$ structures is in agreement with the expected changes in the neptunyl ion coordination. The $\sigma^{2}$ values tend to be lower for $\mathrm{Np}^{\mathrm{VI}}$ than for $\mathrm{Np}^{\mathrm{V}}$ for a given $N_{\text {Oeq. }}$. This result agrees well with the decrease in atomic charge and bonding strength between water and neptunyl units from $\mathrm{Np}^{\mathrm{VI}}$ to $\mathrm{Np}^{\mathrm{V}}$ (Choppin \& Rao, 1984; Denning, 2007).

At this stage, we conclude that the sample preparation, as well as the continuous application of electrochemical potential, is a good way to maintain a pure oxidation state during $\mathrm{X}$-ray measurements resulting in a low conformational $\sigma^{2}$. However, this better oxidation-state purification does not solve the difficult question of the hydration structure of actinyl ions in solution. To evaluate this point further, additional information may be extracted to narrow down the actual $N_{\text {Oeq }}$ values. With this same aim, Ikeda-Ohno et al. (2008) suggested that the $N_{\text {Oeq }}$ values be derived from the more accurately determined interatomic distances applying the bond valence model (Brown, 1978). Although this approach proved to be satisfying for the well-known coordination chemistry of $\mathrm{U}^{\mathrm{VI}}$, application to $\mathrm{Np}$ is plagued by the limited number of crystallographic references and by uncertainties in the valence unit and the charges of the neptunyl moieties, so that $N_{\text {Oeq }}$ values still range between 4 and 6 . Another way to constrain the accurate coordination number is to associate EXAFS analysis with quantum chemical calculations (Vila et al., 2012). For some actinide molecular compounds, it is possible to generate EXAFS metrical parameters from a DFT calculation (Acher et al., 2016, 2017; Dalodière et al., 2018). The calcula- 


\section{actinides physics and chemistry}

Table 2

DFT calculations of $\mathrm{Np}-\mathrm{O}$ bond distances (average values in $\AA$ ) and Debye-Waller factor $\sigma^{2}\left(\AA^{2}\right)$ in $\mathrm{Np}^{\mathrm{V}}$ and $\mathrm{Np}^{\mathrm{VI}}$ hydrated clusters with four and five coordinated water molecules.

\begin{tabular}{lllll}
\hline & $\mathrm{Np}-\mathrm{O}_{\mathrm{yl}}$ & $\sigma^{2}$ & $\mathrm{~Np}-\mathrm{O}_{\text {wat }}$ & $\sigma^{2}$ \\
\hline $\mathrm{Np}^{\mathrm{v}}\left(\mathrm{H}_{2} \mathrm{O}\right)_{4}\left(\mathrm{H}_{2} \mathrm{O}\right)_{8}{ }^{+}$ & 1.80 & 0.0014 & 2.47 & 0.0048 \\
$\mathrm{~Np}^{\mathrm{v}}\left(\mathrm{H}_{2} \mathrm{O}\right)_{5}\left(\mathrm{H}_{2} \mathrm{O}\right)_{10}{ }^{+}$ & 1.82 & 0.0016 & 2.51 & 0.0068 \\
$\mathrm{~Np}^{\mathrm{vI}}\left(\mathrm{H}_{2} \mathrm{O}\right)_{4}\left(\mathrm{H}_{2} \mathrm{O}\right)_{8}{ }^{2+}$ & 1.73 & 0.0012 & 2.32 & 0.0033 \\
$\mathrm{~Np}^{\mathrm{vI}}\left(\mathrm{H}_{2} \mathrm{O}\right)_{5}\left(\mathrm{H}_{2} \mathrm{O}\right)_{10}{ }^{2+}$ & 1.73 & 0.0013 & 2.42 & 0.0050 \\
\hline
\end{tabular}

tion provides distances and $\sigma^{2}$ values ab initio from a selected structure. The $\mathrm{NpO}_{2}\left(\mathrm{H}_{2} \mathrm{O}\right)_{4}\left(\mathrm{H}_{2} \mathrm{O}\right)_{8}{ }^{2+}, \mathrm{NpO}_{2}\left(\mathrm{H}_{2} \mathrm{O}\right)_{5}\left(\mathrm{H}_{2} \mathrm{O}\right)_{10}{ }^{2+}$, $\mathrm{NpO}_{2}\left(\mathrm{H}_{2} \mathrm{O}\right)_{4}\left(\mathrm{H}_{2} \mathrm{O}\right)_{8}{ }^{+}$and $\mathrm{NpO}_{2}\left(\mathrm{H}_{2} \mathrm{O}\right)_{5}\left(\mathrm{H}_{2} \mathrm{O}\right)_{10}{ }^{+}$complexes in the presence of a continuum solvent model were selected to produce the parameters reported in Table 2. The accuracy of the optimized geometry was checked by direct comparison of $\mathrm{Np}-\mathrm{O}_{\mathrm{eq}}$ bond lengths with the measurements. This type of calculation provides an estimated value for the thermal $\sigma^{2}$ for a given coordination number and for both $\mathrm{Np}^{\mathrm{V}}$ and $\mathrm{Np}^{\mathrm{VI}}$. It was possible to compare it with the experimental fit values in Fig. 5 (red and blue open circles). For both $\mathrm{Np}^{\mathrm{VI}}$ and $\mathrm{Np}^{\mathrm{V}}$, interestingly, $\sigma^{2}$ follows the same trend as already observed for experimental fit parameters. However, this trend is obviously not due to the correlation of EXAFS fit parameters since the two values $\left(\mathrm{CN}\right.$ and $\left.\sigma^{2}\right)$ are determined independently. This inquires a physical interrelation between a bonding strength and the actinyl coordination number in actinyl solvation. This effect fundamentally impedes the direct determination of actinyl solvatation using the amplitude of the equatorial scattering shell in the EXAFS signal. Again, using distances from both EXAFS and DFT to discriminate between pentaand tetrahydrated neptunyl ions seems a more reliable method. For $\mathrm{Np}^{\mathrm{V}}$ with five water molecules, both the calculation and the fit converge for a $2.51 \AA$ bond. For $\mathrm{Np}^{\mathrm{VI}}$ with five water molecules, 2.41 and $2.42 \AA$ bond lengths are obtained from the fit and the calculation, respectively. Overall, the results support the fact that five water molecules coordinate both the $\mathrm{Np}^{\mathrm{VI}}$ and the $\mathrm{Np}^{\mathrm{V}}$ ions.

\section{2. $\mathrm{Np}^{\mathrm{V}} / \mathrm{Np}^{\mathrm{IV}}$}

To evaluate further the electrochemistry setup, a second electrolysis experiment was performed following the previous one. After stabilizing the $+\mathrm{V}$ oxidation state by a $1 \mathrm{~h}$ electrolysis at $750 \mathrm{mV} /(\mathrm{Ag} / \mathrm{AgCl})$, the $\mathrm{Np}^{\mathrm{V}}$ purity was checked again using XANES and EXAFS. Next, the $\mathrm{Np}^{\mathrm{V}}$ reduction was investigated by a stepwise decrease of the applied potential to $0,-100,-150,-200$ and $-250 \mathrm{mV} /(\mathrm{Ag} / \mathrm{AgCl})$. In $\mathrm{HNO}_{3}$ solution, the $\mathrm{Np}^{\mathrm{IV}}$ ion is difficult to stabilize due to its reoxidation with $\mathrm{HNO}_{2}$ in equilibrium with nitrate ions (Taylor et al., 1998; Koltunov et al., 1997). The corresponding XANES spectra are displayed on Fig. 4. Consistent with previous XANES measurements, the $\mathrm{Np} L_{3}$-edge drastically changes due to cleavage of the two $\mathrm{Np}-\mathrm{O}$ bonds in the neptunyl moiety (Bonin et al., 2009; Denecke et al., 2005; Hennig et al., 2009; Scheinost et al., 2016). Actinide reduction from $+\mathrm{V}$ to $+\mathrm{IV}$ results in an increase of the white line

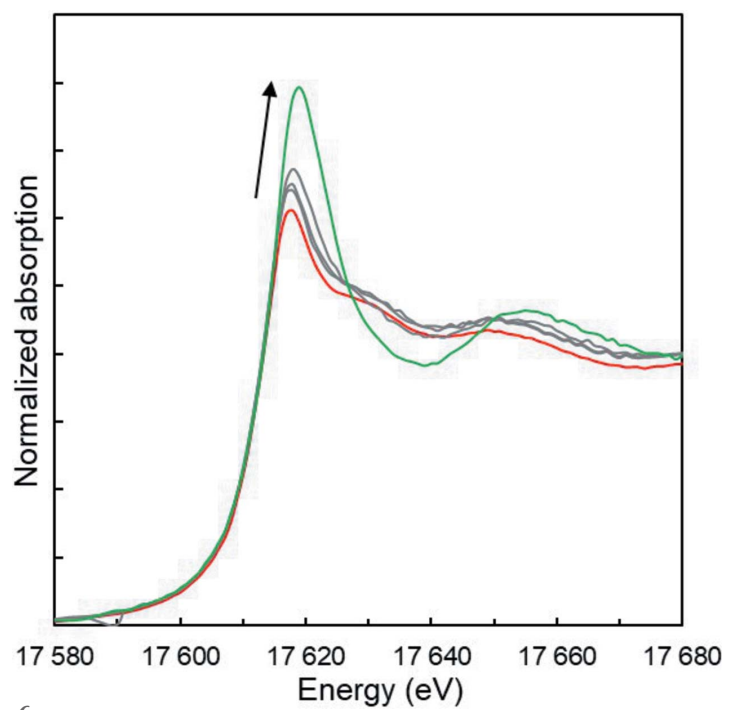

Figure 6

Normalized $\mathrm{Np} L_{3}$-edge XANES spectrum for the $\mathrm{Np}^{\mathrm{V}}$ reduction experiment at $750,0,-100,-150,-200$ and $-250 \mathrm{mV} /(\mathrm{Ag} / \mathrm{AgCl})$.

intensity and a decrease in the amplitude of the higher-energy shoulder at $17637 \mathrm{eV}$. However, the edge inflection point is almost stabilized by the reduction. XANES spectra are consistent with previous ex situ studies and indicate an almost complete reduction of $\mathrm{Np}^{\mathrm{V}}$ to $\mathrm{Np}^{\mathrm{IV}}$. More unexpected is the corresponding potential at which this electroreduction occurred. As shown in Fig. 6, it was mostly $\mathrm{Np}^{\mathrm{V}}$ that was detected in solution at the potential step of $0 \mathrm{mV}$. At -100 and $-150 \mathrm{mV}$, the spectra indicate mixed $\mathrm{Np} / \mathrm{Np}^{\mathrm{IV}}$ contributions. Quantitative $\mathrm{Np}^{\mathrm{V}}$ reduction is eventually achieved at -200 and $-250 \mathrm{mV}$.

According to recent work (Chatterjee et al., 2017), reduction to $\mathrm{Np}^{\mathrm{IV}}$ is expected to occur at approximately $50 \mathrm{mV} /(\mathrm{Ag} / \mathrm{AgCl})$ in $1 M \mathrm{HNO}_{3}$. Moreover, one would also expect a reduction to the $\mathrm{Np}^{\mathrm{III}}$ oxidation state below $-100 \mathrm{mV} /(\mathrm{Ag} / \mathrm{AgCl})$. The $\mathrm{Np}^{\mathrm{IV}} / \mathrm{Np}^{\mathrm{III}}$ redox potential was determined at approximately $-50 \mathrm{mV}$ (Guillaumont et al., 2003). In such a case, the resulting neptunium $L_{3}$ spectra would be a combination of the two redox species. However, $\mathrm{Np}^{\text {III }}$ is unstable under aerobic conditions and only $\mathrm{Np}^{\text {IV }}$ seems to be present in the solution after this enforced electrolysis (Hindman et al., 1949; Sjoblom \& Hindman, 1951; Sullivan et al., 1976; Cohen, 1976).

5.2.1. EXAFS analysis. From electrolysis experiments and analysis of XANES spectra, we demonstrated that it is possible to obtain $\mathrm{Np}^{\mathrm{IV}}$ by electrolysis at $-250 \mathrm{mV}$. The $k^{3}$ weighted $\mathrm{Np} L_{3}$-edge EXAFS spectrum of $\mathrm{Np}^{\mathrm{IV}}$ hydrate shows a single-frequency oscillation (Fig. 7) and the corresponding FT displays a single peak which can be reliably modelled with a single $\mathrm{Np}-\mathrm{O}$ coordination shell. The structural parameters from this fit are summarized in Table 3. The best fit values correspond to approximately $9.5 \mathrm{O}$ atoms (from water molecules), with an average $R_{(\mathrm{Np}-\mathrm{O})}$ distance of $2.39 \AA$.

The $\mathrm{Np}-\mathrm{O}$ distance corresponds to the values reported in the literature of 2.37-2.41 $\AA$ (Combes et al., 1992; Allen et al., 1997; Reich et al., 2000; Williams et al., 2001; Bolvin et al., 2001; 
Table 3

Parameters from $\mathrm{Np}^{\mathrm{IV}}$ EXAFS fits.

Asterisks (*) indicate fixed parameters.

\begin{tabular}{lllll}
\hline & Path & $\mathrm{CN}$ & $R$ & $\sigma^{2}$ \\
\hline$S_{0}^{2} 1^{*}$ & $\mathrm{O}_{\mathrm{H} 2 \mathrm{O}}$ & $9.5(16)$ & $2.39(2)$ & $0.0095(15)$ \\
$\Delta E_{0}-4 \mathrm{eV}$ & & & & \\
$R$ factor $3.8 \%$ & & & & \\
\hline
\end{tabular}

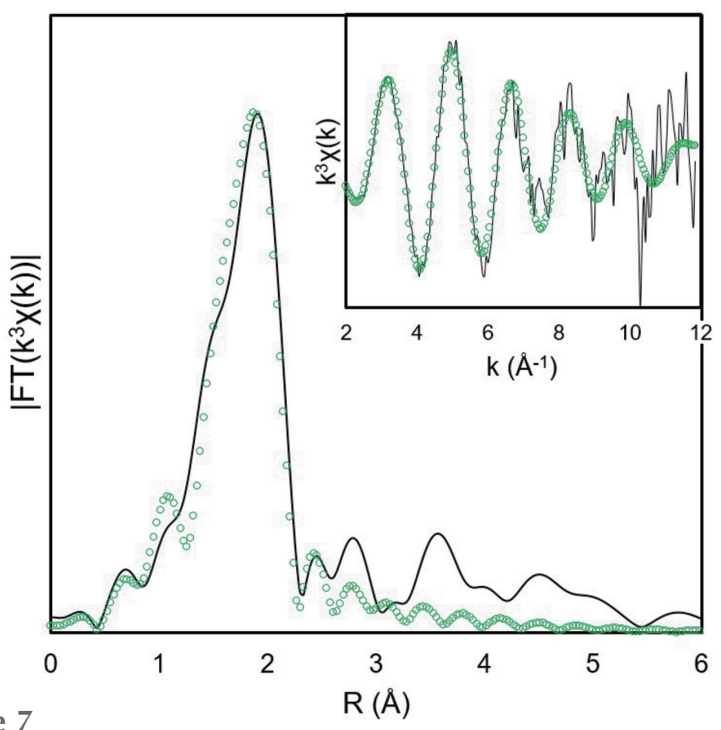

Figure 7

Experimental $k^{3}$-weighted EXAFS oscillations (line) and best fits (open circles) obtained after $30 \mathrm{~min}$ electrolysis at $-250 \mathrm{mV}$ (green).

Antonio et al., 2001). The $N_{\mathrm{H} 2 \mathrm{O}}$ value also falls within the range of previous EXAFS results for $\mathrm{Np}^{\mathrm{IV}}$ aqua complexes, i.e. between 8.7 and 11.6 (Combes et al., 1992; Allen et al., 1997; Reich et al., 2000; Williams et al., 2001; Bolvin et al., 2001; Antonio et al., 2001).

As for $\mathrm{Np}^{\mathrm{V}}$ and $\mathrm{Np}^{\mathrm{VI}}$, a clear correlation between $\sigma^{2}$ and $N_{\mathrm{O}}$ can be drawn with restricted $N_{\mathrm{O}}$ fits. Fixing $N_{\mathrm{O}}$ from 8 to 11 allows the determination of the corresponding $\sigma^{2}$. These values approximately align as a function of $N_{\mathrm{O}}$ (Fig. 8, green dashed line), together with the best fit values (triangle). The corresponding data determined previously on analogous systems are compared (grey diamond). Interestingly, almost all previous studies report a lower $\sigma^{2}$ value for a given $N_{\mathrm{O}}$ compared with the present report. The more distorted geometry of the 8 to 11 water molecule coordination shell results in $\sigma^{2}$ values (from 0.0065 to $0.012 \AA^{2}$ ) much larger than observed for the neptunyl hydration shell. This time the comparison with previous studies clearly indicates a residual disorder in the neptunium coordination sphere for the in situ prepared $\mathrm{Np}^{4+}$. This may be explained by either (i) a residual $\mathrm{NpO}_{2}{ }^{+}$contribution in the EXAFS spectrum, (ii) overreduction resulting in the formation of $\mathrm{Np}^{\mathrm{III}}$ with a coordination shell at about $2.5 \AA$ (Antonio et al., 2001; Brendebach et al., 2009) or (iii) complexation of $\mathrm{Np}^{\mathrm{IV}}$ by nitrate (by analogy with $\mathrm{Pu}^{\mathrm{IV}}$ chemistry in nitric acid this must be quite insignificant; Allen et al., 1996), or a combination of points (i), (ii) and (iii).

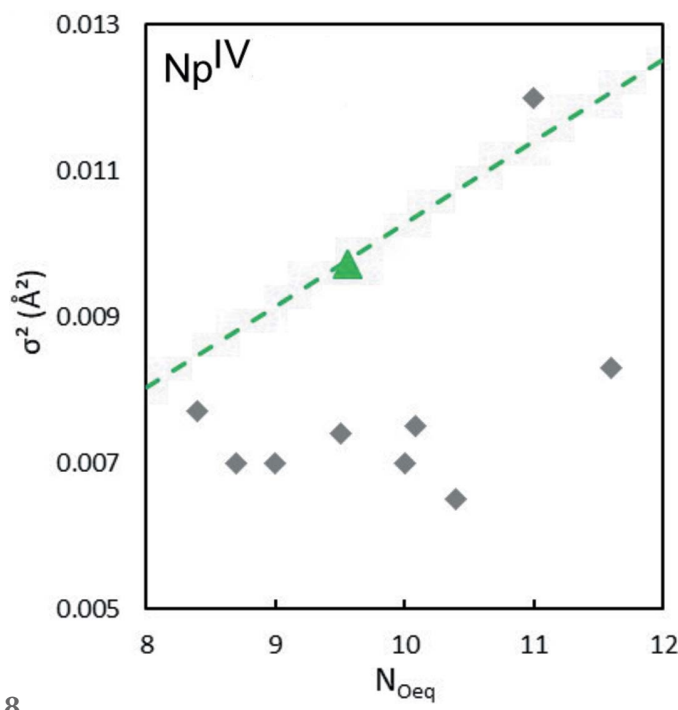

Figure 8

Plot of the $\sigma^{2}$ values as a function of coordination number from the EXAFS fit (dashed line) and comparison with previously reported values (Antonio et al., 2001; Ikeda-Ohno et al., 2008, 2009; Hennig et al., 2009; Di Giandomenico et al., 2009; Combes et al., 1992; Allen et al., 1997; Reich et al., 2000; Scheinost et al., 2016; Denecke et al., 2005) (grey diamonds). The triangle shows the best fit results from this work.

\section{Conclusions}

The main aim of this study was to develop a spectroelectrochimical cell and to qualify this setup for further applications on radioactive samples. During the experiment, it was possible to investigate the neptunium coordination during redox processes in a simple $1 M \mathrm{HNO}_{3}$ solution.

The technical parameters of the microcell design are presented herein and its first application to transuranic elements, performed safely, are reported. The cell design minimizes the volume of radioactive solution and facilitates transport and handling on the beamline. Low actinide concentration and volume minimize the sample activity and allows XANES and EXAFS measurements within a reasonable timescale. From an electrochemistry point of view, such a static confinement concept is not ideal. On one hand, cycling the $\mathrm{NpO}_{2}{ }^{2+} / \mathrm{NpO}_{2}{ }^{+}$redox couple was quite possible and resulted in reliable standard potential determination. It was then possible to measure both $\mathrm{Np}^{\mathrm{V}}$ and $\mathrm{Np}^{\mathrm{VI}}$ EXAFS spectra under fully consistent conditions. This was a good opportunity to compare the $\mathrm{Np}^{\mathrm{V}}$ and $\mathrm{Np}^{\mathrm{VI}}$ hydration spheres, and to implement a statistical comparison with formal literature results, as well as theoretical models. The evolution in the equatorial actinyl hydration is well characterized and is consistent with theoretical expectations. Moreover, a detailed comparison with previous structural data using EXAFS established that the stabilization of $\mathrm{Np}^{\mathrm{V}}$ and $\mathrm{Np}^{\mathrm{VI}}$ oxidation by in situ electrochemistry appears to be the most reliable way to maintain a pure oxidation state during X-ray measurements. On the other hand, the reduction to $\mathrm{Np}^{\mathrm{IV}}$ never fully succeeded in maintaining pure $\mathrm{Np}^{\mathrm{IV}}$ in solution. From the point of view of electrochemistry, a clear offset in the expected standard potential must be applied to begin the $\mathrm{Np}^{\mathrm{V}}$ reduction. The resulting $\mathrm{Np}^{\text {IV }}$ EAXFS spectra reveal hydrated $\mathrm{Np}^{4+}$ 
as the main species, but comparison with a previous chemically stabilized $\mathrm{Np}^{\mathrm{IV}}$ solution indicates a more disordered coordination sphere. Altogether, it seems that, while the results are fully satisfying for the oxidized neptunium species, the cell must be used with care to study reduced neptunium forms. As a final point, this cell, primarily designed to confine radioactive samples for user safety, was also efficient for performing measurements on nonradioactive samples. Its design for radioactive samples appears to be versatile and extremely convenient for preventing moisture and oxygen contaminating air-sensitive samples in the reverse direction. By doing so, the in situ XAS stabilization and characterization of $\mathrm{Ln}^{\mathrm{II}}$ in roomtemperature ionic liquid samples was made possible with this cell (Bengio et al., 2018, 2020) and other applications of this kind are expected.

\section{References}

Acher, E., Dumas, T., Tamain, C., Boubals, N., Solari, P. L. \& Guillaumont, D. (2017). Dalton Trans. 46, 3812-3815.

Acher, E., Hacene Cherkaski, Y., Dumas, T., Tamain, C., Guillaumont, D., Boubals, N., Javierre, G., Hennig, C., Solari, P. L. \& Charbonnel, M. C. (2016). Inorg. Chem. 55, 5558-5569.

Achilli, E., Minguzzi, A., Visibile, A., Locatelli, C., Vertova, A., Naldoni, A., Rondinini, S., Auricchio, F., Marconi, S., Fracchia, M. \& Ghigna, P. (2016). J. Synchrotron Rad. 23, 622-628.

Allen, P. G., Bucher, J. J., Shuh, D. K., Edelstein, N. M. \& Reich, T. (1997). Inorg. Chem. 36, 4676-4683.

Allen, P. G., Veirs, D. K., Conradson, S. D., Smith, C. A. \& Marsh, S. F. (1996). Inorg. Chem. 35, 2841-2845.

Antonio, M. R., Soderholm, L. \& Song, I. (1997). J. Appl. Electrochem. 27, 784-792.

Antonio, M. R., Williams, C. W. \& Soderholm, L. (2002). Radiochim. Acta, 90, 851-856.

Antonio, M. R., Williams, C. W., Sullivan, J. A., Skanthakumar, S., Hu, Y. J. \& Soderholm, L. (2012). Inorg. Chem. 51, 5274-5281.

Antonio, R., Soderholm, L., Williams, C. W., Blaudeau, J. P. \& Bursten, B. E. (2001). Radiochim. Acta, 89, 17-26.

Bengio, D., Dumas, T., Arpigny, S., Husar, R., Mendes, E., Solari, P. L., Schlegel, M. L., Schlegel, D., Pellet-Rostaing, S. \& Moisy, P. (2020). Chem. Eur. J. 26, 14385-14396.

Bengio, D., Dumas, T., Mendes, E., Solari, P. L., Husar, R., Schlegel, M., Moisy, P. \& Pellet-Rostaing, S. (2018). Rare Metal Technology 2018, pp. 99-112. Part of the The Minerals, Metals \& Materials Series book series. Switzerland: Springer Nature.

Bolvin, H., Wahlgren, U., Moll, H., Reich, T., Geipel, G., Fanghänel, T. \& Grenthe, I. (2001). J. Phys. Chem. A, 105, 11441-11445.

Bonin, L., Guillaumont, D., Jeanson, A., Den Auwer, C., Grigoriev, M., Berthet, J. C., Hennig, C., Scheinost, A. \& Moisy, P. (2009). Inorg. Chem. 48, 3943-3953.

Brendebach, B., Banik, N. L., Marquardt, C. M., Rothe, J., Denecke, M. A. \& Geckeis, H. (2009). Radiochim. Acta, 97, 701-708.

Brown, I. D. (1978). Chem. Soc. Rev. 7, 359-376.

Cao, X. Y. \& Dolg, M. (2004). J. Mol. Struct. Theochem. 673, 203-209.

Chatterjee, S., Bryan, S. A., Casella, A. J., Peterson, J. M. \& Levitskaia, T. G. (2017). Inorg. Chem. Front. 4, 581-594.

Choppin, G. R. \& Rao, L. F. (1984). Radiochimica Acta, 37, 143-146. Cohen, D. (1961). J. Inorg. Nucl. Chem. 18, 207-210.

Cohen, D. (1976). Abstr. Pap. Am. Chem. Soc. 172, 28.

Cohen, D. \& Hindman, J. C. (1952). J. Am. Chem. Soc. 74, 4679-4682.

Cohen, D., Sullivan, J. C. \& Hindman, J. C. (1954). J. Am. Chem. Soc. 76, 352-354.
Combes, J. M., Chisholm-Brause, C. J., Brown, G. E., Parks, G. A., Conradson, S. D., Eller, P. G., Triay, I. R., Hobart, D. E. \& Miejer, A. (1992). Environ. Sci. Technol. 26, 376-382.

Dalodière, E., Virot, M., Dumas, T., Guillaumont, D., Illy, M. C., Berthon, C., Guerin, L., Rossberg, A., Venault, L., Moisy, P. \& Nikitenko, S. I. (2018). Inorg. Chem. Front. 5, 100-111.

Den Auwer, C., Revel, R., Charbonnel, M. C., Presson, M. T., Conradson, S. D., Simoni, E., Le Du, J. F. \& Madic, C. (1999). J. Synchrotron Rad. 6, 101-104.

Denecke, M. A., Dardenne, K. \& Marquardt, C. M. (2005). Talanta, 65, 1008-1014.

Denning, R. G. (2007). J. Phys. Chem. A, 111, 4125-4143.

Di Giandomenico, M. V., Naour, C. L., Simoni, E., Guillaumont, D., Moisy, P., Hennig, C., Conradson, S. D. \& Den Auwer, C. (2009). Radiochim. Acta, 97, 347-353.

Duvail, M., Dumas, T., Paquet, A., Coste, A., Berthon, L. \& Guilbaud, P. (2019). Phys. Chem. Chem. Phys. 21, 7894-7906.

Frisch, M. J., et al. (2016). GAUSSIAN16. Revision B.01. GaussView Version 5.0. Gaussian Inc., Wallingford, CT, USA.

Guillaumont, R., Fanghänel, T., Fuger, J., Grenthe, I., Neck, V., Palmer, D. A. \& Rand, M. H. (2003). Update on the Chemical Thermodynamics of $\mathrm{U}, \mathrm{Np}, \mathrm{Pu}, \mathrm{Am}$ and $\mathrm{Tc}$, Vol. 5. Amsterdam: Elsevier.

Hennig, C., Ikeda-Ohno, A., Tsushima, S. \& Scheinost, A. C. (2009). Inorg. Chem. 48, 5350-5360.

Hennig, C., Tutschku, J., Rossberg, A., Bernhard, G. \& Scheinost, A. C. (2005). Inorg. Chem. 44, 6655-6661.

Hindman, J. C., Magnusson, L. B. \& LaChapelle, T. J. (1949). J. Am. Chem. Soc. 71, 687-693.

Hindman, J. C., Sullivan, J. C. \& Cohen, D. (1958). J. Am. Chem. Soc. 80, 1812-1814.

Ikeda-Ohno, A., Hennig, C., Rossberg, A., Funke, H., Scheinost, A. C., Bernhard, G. \& Yaita, T. (2008). Inorg. Chem. 47, 8294-8305.

Ikeda-Ohno, A., Hennig, C., Tsushima, S., Scheinost, A. C., Bernhard, G. \& Yaita, T. (2009). Inorg. Chem. 48, 7201-7210.

Jeanson, A., Dahou, S., Guillaumont, D., Moisy, P., Auwer, C. D., Scheinost, A., Hennig, C., Vidaud, C., Subra, G. \& Solari, P. L. (2009). J. Phys. Conf. Ser. 190, 012185.

Kihara, S., Yoshida, Z., Aoyagi, H., Maeda, K., Shirai, O., Kitatsuji, Y. \& Yoshida, Y. (1999). Pure Appl. Chem. 71, 1771-1807.

Kim, S. Y., Asakura, T. \& Morita, Y. (2005). Radiochim. Acta, 93, 767770.

Kim, S. Y., Asakura, T., Morita, Y., Uchiyama, G. \& Ikeda, Y. (2004). J. Radioanal. Nucl. Chem. 262, 311-315.

Koltunov, V. S., Taylor, R. J., Savilova, O. A., Zhuravleva, G. I., Denniss, I. S. \& Wallwork, A. L. (1997). Radiochim. Acta, 76, 45-54.

Küchle, W., Dolg, M., Stoll, H. \& Preuss, H. (1994). J. Chem. Phys. 100, 7535-7542.

LLorens, I., Solari, P. L., Sitaud, B., Bes, R., Cammelli, S., Hermange, H., Othmane, G., Safi, S., Moisy, P., Wahu, S., Bresson, C., Schlegel, M. L., Menut, D., Bechade, J. L., Martin, P., Hazemann, J. L., Proux, O. \& Den Auwer, C. (2014). Radiochim. Acta, 102, 957-972.

Nockemann, P., Thijs, B., Lunstroot, K., Parac-Vogt, T. N., GörllerWalrand, C., Binnemans, K., Van Hecke, K., Van Meervelt, L., Nikitenko, S., Daniels, J., Hennig, C. \& Van Deun, R. (2009). Chem. Eur. J. 15, 1449-1461.

Poineau, F., Fattahi, M. \& Grambow, B. (2006). Radiochim. Acta, 94, 559-563.

Ravel, B. \& Newville, M. (2005). J. Synchrotron Rad. 12, 537-541.

Rehr, J. J. \& Albers, R. C. (2000). Rev. Mod. Phys. 72, 621-654.

Rehr, J. J., Kas, J. J., Vila, F. D., Prange, M. P. \& Jorissen, K. (2010). Phys. Chem. Chem. Phys. 12, 5503-5513.

Reich, T., Bernhard, G., Geipel, G., Funke, H., Hennig, C., Roßberg, A., Matz, W., Schell, N. \& Nitsche, H. (2000). Radiochim. Acta, 88, 633-638.

Schäfer, A., Huber, C. \& Ahlrichs, R. (1994). J. Chem. Phys. 100, 5829-5835. 
Scheinost, A. C., Steudtner, R., Hübner, R., Weiss, S. \& Bok, F. (2016). Environ. Sci. Technol. 50, 10413-10420.

Sjoblom, R. \& Hindman, J. C. (1951). J. Am. Chem. Soc. 73, 17441751.

Soderholm, L., Antonio, M. R., Williams, C. \& Wasserman, S. R. (1999). Anal. Chem. 71, 4622-4628.

Sornein, M. O., Mendes, M., Cannes, C., Le Naour, C., Nockemann, P., Van Hecke, K., Van Meervelt, L., Berthet, J. C. \& Hennig, C. (2009). Polyhedron, 28, 1281-1286.

Sullivan, J. C., Gordon, S., Cohen, D., Mulac, W. \& Schmidt, K. H. (1976). J. Phys. Chem. 80, 1684-1686.
Takao, K., Takao, S., Scheinost, A. C., Bernhard, G. \& Hennig, C. (2009). Inorg. Chem. 48, 8803-8810.

Taylor, R. J., Koltunov, V. S., Savilova, O. A., Zhuravleva, G. I., Denniss, I. S. \& Wallwork, A. L. (1998). J. Alloys Compd. 271-273, 817-820.

Vila, F. D., Lindahl, V. E. \& Rehr, J. J. (2012). Phys. Rev. B, 85, 024303.

Williams, C. W., Blaudeau, J. P., Sullivan, J. C., Antonio, M. R., Bursten, B. \& Soderholm, L. (2001). J. Am. Chem. Soc. 123, 43464347.

Zielen, A. J., Sullivan, J. C. \& Cohen, D. (1958). J. Inorg. Nucl. Chem. 7, 378-383. 